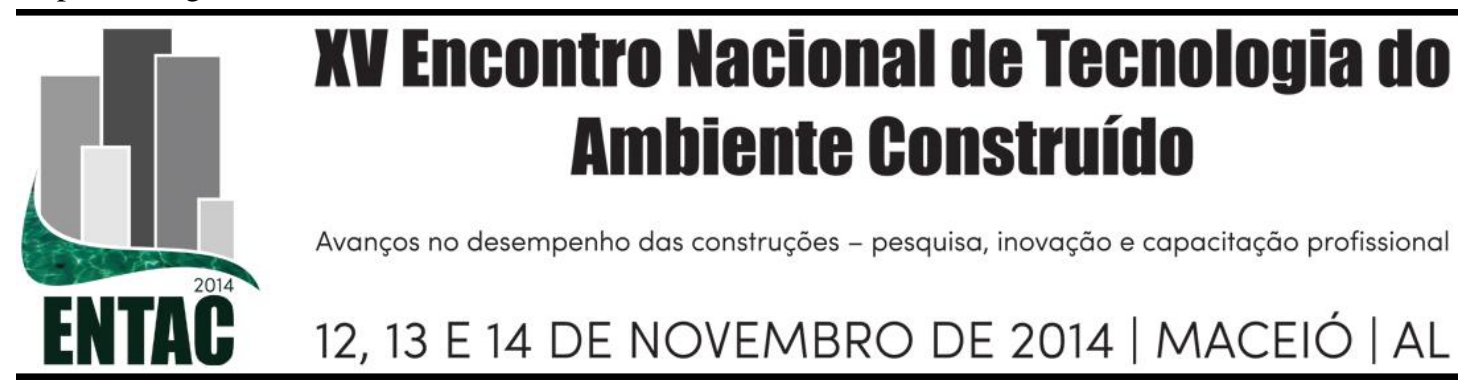

\title{
ANÁLISE COMPARATIVA ENTRE DESEMPENHO LUMINOSO E EFICIÊNCIA ENERGÉTICA UTILIZANDO O TROPLUX
}

\author{
PASSOS, Isabela (1); LAMENHA, Melyna (2); CABÚS, Ricardo (3)
}

(1) UFAL, e-mail: isabela.arquitetura@gmail.com (2) UFAL, e-mail: melynalamenha@gmail.com, (3)

UFAL, e-mail: ricardo.cabus@gmail.com

\begin{abstract}
RESUMO
O uso da iluminação natural de maneira adequada oferece maior qualidade e eficiência energética ao ambiente construído. O correto dimensionamento das aberturas pode garantir o bom funcionamento da iluminação nos ambientes, utilizando a luz artificial apenas de maneira complementar. Em edificações residenciais populares o uso da iluminação natural torna-se ainda mais importante considerando que a população de baixa renda não tem condições de arcar com gastos extras de iluminação artificial para corrigir erros de projeto. Os programas governamentais de habitação popular produzem habitações padronizadas em todo o país. Na maioria dos casos essas habitações não se adéquam ao clima local das cidades tornando-se, muitas vezes desconfortáveis e de baixa eficiência energética. Diversas medidas vêm sendo tomadas a fim de minimizar os gastos desnecessários com energia elétrica nas edificações. Uma delas foi o lançamento do Regulamento Técnico da Qualidade do Nível de Eficiência Energética das Edificações Residenciais, o RTQ-R que lança diretrizes para avaliação do nível de eficiência energética das edificações, classificando-as com uma Etiqueta Nacional de Conservação de Energia (ENCE). O objetivo do artigo é analisar os resultados obtidos na avaliação do pré-requisito e bonificação de iluminação natural propostos pelo RTQ-R em comparação com estudos paramétricos feitos através do software TropLux. Foram simulados quatro modelos com diferentes áreas de abertura, orientações e cores de paredes, simulando o caso real de um edifício localizado na cidade de Maceió-AL. Os ambientes que não atenderam ao pré-requisito de área de abertura para iluminação natural do RTQ-R, apresentam iluminâncias adequadas ao uso. As mudanças das áreas de abertura para iluminação natural, da cor da parede e da orientação solar, não causaram prejuízo no desempenho da iluminação natural nos ambientes analisados. Este trabalho é resultado de estudos realizados em disciplina de pós-graduação.
\end{abstract}

Palavras-chave: Iluminação natural, Eficiência energética, Simulação computacional.

\begin{abstract}
The proper use of natural lighting provides higher quality and efficiency to the built environment. The correct sizing of the openings can guarantee the proper functioning of the lighting in the environment, using artificial light only in a complementary way. In popular residential buildings use of natural lighting becomes even more important considering that the low-income population is unable to afford extra expenses of artificial lighting to correct design errors. Government programs for housing dwellings produce standardized across the country. In most cases these dwellings do not suit the local climate of the cities making it often uncomfortable and low energy efficiency level. Several measures have been taken to minimize unnecessary spending on electricity in buildings. One was the launch of the Technical Regulation on Quality Level Energy Efficiency of Residential Buildings, the RTQ-R which launches guidelines for assessing the level of energy efficiency of buildings, classifying them with a Label National Energy Conservation (ENCE). The aim of this paper is to analyze the results obtained in the evaluation of the prerequisite and credit daylighting proposed by $R T Q-R$ compared with parametric studies made by software TropLux. Four models were simulated by the software Troplux with different opening areas, orientations and colors of walls, simulating the real case of a building located in the city of Maceió-AL, related to daylight. The rooms that did not meet the prerequisite of opening area for natural lighting of
\end{abstract}


the $R T Q-R$, present levels of illuminance appropriate to use. Changes in opening areas for natural lighting, wall color and solar orientation, did not cause injury in the performance of natural lighting inside the analyzed rooms.

Keywords: Daylight, Energy efficiency, Computer simulation.

\section{INTRODUÇÃO}

O uso da luz natural na arquitetura é uma estratégia eficaz para a obtenção de maior qualidade ambiental e eficiência energética. Regular a entrada de luz do sol no interior das edificações é fundamental para fornecer aos ambientes, salubridade e conforto luminoso. No Brasil, país de clima tropical, tem-se abundância de luz solar e cabe aos arquitetos e projetistas utilizá-la de maneira adequada, pois o excesso de luz natural pode provocar ofuscamento e desconforto visual enquanto que sua escassez pode levar ao uso desnecessário de energia elétrica.

Segundo Ghisi e Tinker (2005) especificar o tamanho correto de abertura, buscando um equilíbrio entre a entrada de luz natural e ganhos térmicos levará a um uso otimizado da energia elétrica na edificação.

O uso da iluminação natural em habitações populares é importante considerando o impacto que o consumo desnecessário de energia elétrica pode causar nas faixas de renda mais baixas da população. As políticas públicas para atenuação do déficit habitacional brasileiro, tem criado programas governamentais para construção de novas unidades, entretanto, a necessidade de produção de habitações em massa e a baixos custos, reduz a qualidade ambiental das mesmas, gerando desconforto térmico e luminoso dos usuários, além de baixa eficiência energética.

O INMETRO, em conjunto com o Governo Brasileiro, tem motivado o uso de estratégias projetuais que melhorem os níveis de eficiência energética em edifícios. A publicação do Regulamento Técnico da Qualidade para o Nível de Eficiência Energética de Edificações Residenciais - RTQ-R (BRASIL, 2012), em 2010, alavancou a avaliação do nível de eficiência energética em habitações.

O objetivo principal deste artigo é avaliar o desempenho luminoso em ambientes de permanência prolongada de edificações residenciais populares que foram submetidas a avaliação pelo método prescritivo do RTQ-R (BRASIL, 2012), confrontando os resultados da análise de iluminação natural e eficiência energética.

\section{METODOLOGIA}

A metodologia do presente trabalho baseia-se em uma pesquisa aplicada através de análises paramétricas comparativas de modelos computacionais construídos com diferentes configurações, observando os efeitos produzidos pela iluminação natural no conforto visual dos usuários e na eficiência energética da edificação em estudo.

A seguir, descrevem-se os procedimentos metodológicos adotados.

\subsection{Análise de pré-requisito e bonificação de iluminação natural segundo RTQ-R (BRASIL, 2012)}

A classificação do nível de eficiência energética segundo o RTQ-R, pode ser feita pelos métodos prescritivo ou de simulação computacional. O método prescritivo estabelece pré-requisitos para a classificação da envoltória (conjunto de planos que separam o ambiente interno do ambiente externo). Tais pré-requisitos devem ser atendidos para que seja obtido o nível máximo de eficiência energética calculado. 
Além disto, ao final da avaliação por meio do método prescritivo é permitida a soma de bonificações à pontuação final. Estas bonificações podem ser de ventilação natural, de iluminação natural, do uso racional de água, entre outras.

Para atender ao pré-requisito de iluminação natural, a soma das áreas de aberturas para iluminação natural de cada ambiente deve corresponder a no mínimo $12,50 \%$ da área útil do ambiente. O não atendimento a este pré-requisito permite no máximo nível $\mathrm{C}$ nos equivalentes numéricos da envoltória do ambiente para resfriamento e para refrigeração.

A bonificação de iluminação natural vale no máximo 0,30 pontos, sendo 0,20 pontos relativos à profundidade $(\mathrm{P})$ dos ambientes (Equação 1$)$ e 0,10 pontos para a refletância do teto acima de $60,00 \%$.

$$
P \leq 2,4 \cdot h_{a}
$$

onde, $\mathrm{P}=$ profundidade do ambiente $(\mathrm{m})$;

ha = distância medida entre o piso e a altura máxima da abertura para iluminação (m),excluindo caixilhos.

Sendo assim, foi analisado o atendimento ao pré-requisito de iluminação natural e verificada a bonificação de iluminação natural que o edifício em estudo receberia caso submetido ao RTQ-R.

\subsection{Análises paramétricas através de simulação computacional no software TropLux}

O modelo corresponde a um condomínio residencial construído na cidade de MaceióAL, no bairro da Serraria, dentro do Programa de Arrendamento Residencial PAR do Governo Brasileiro. O Condomínio Mayra, faz parte do complexo residencial Aldeota, juntamente com outros dois condomínios: o Janaína e o Iracema. Seu projeto é de 2004, mas a obra foi entregue aos arrendatários em 2008 (Figura 1).

Os blocos contêm quatro pavimentos cada, sendo quatro apartamentos em cada andar. Os apartamentos são compostos de dois quartos, uma sala, uma cozinha e um banheiro, com área de aproximadamente $36,20 \mathrm{~m}^{2}$. Este condomínio foi escolhido por ser uma tipologia de edificação habitacional popular bastante recorrente nas cidades do país.

Figura 1 - Planta baixa e imagem dos apartamentos do Condomínio Mayra
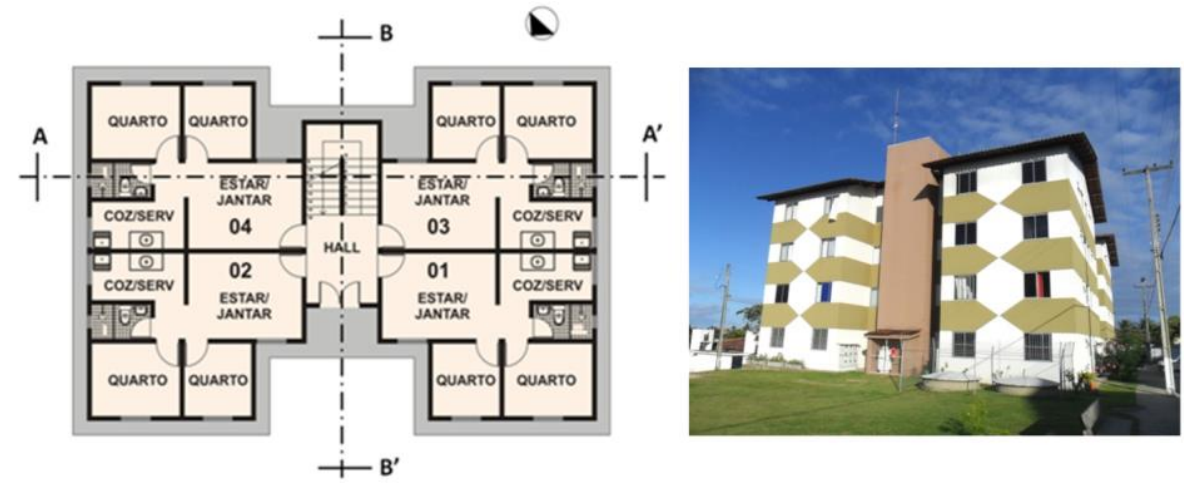

Fonte: Autor (2013)

Para o presente trabalho, foram analisadas a sala e a cozinha por serem ambientes mais utilizados durante o dia e onde há maior desenvolvimento de tarefas que podem exigir acuidade visual. 
O software TropLux 6.0 (CABÚS, 2005-a, 2005-b; RAMOS; GHISI, 2008), permite a simulação do desempenho da iluminação natural considerando o clima tropical. Por meio da ferramenta de simulação computacional TropLux, é possível obter os valores absolutos de iluminância, assim como os gráficos de isoiluminâncias dos ambientes.

Para as simulações computacionais foram adotadas três etapas de procedimentos, sendo elas: a construção do modelo base, a elaboração da matriz de parâmetros a serem analisados e as simulações.

Primeiramente foi construída a geometria do modelo considerando a sala, a cozinha e o banheiro, a fim de reproduzir com fidelidade a situação real dos ambientes. O modelo foi construído inicialmente no software SketchUp para facilitar o conhecimento das coordenadas a serem inseridas no TropLux. Em seguida foi elaborada uma matriz com os parâmetros a serem analisados: áreas das aberturas para iluminação (área existente e área acrescida em 40,00\% na sala e 5,00\% na cozinha, considerando as limitações da planta), cor da parede interna aos ambientes, comumente pintada pelos moradores do edifício em estudo (branca e verde) e orientação, totalizando quatro modelos a serem construídos no programa (Quadro 1). Isto porque o TropLux já simula cada modelo para as quatro orientações padrões $0^{\circ}, 90^{\circ}, 180^{\circ}$ e $270^{\circ}$.

Quadro 1 - Modelos e parâmetros analisados nas simulações com o TropLux

\begin{tabular}{|c|c|c|c|c|c|c|}
\hline N. & Nome modelo & Orientações & $\begin{array}{c}\text { Área } \\
\text { de piso } \\
\left(\mathbf{m}^{2}\right)\end{array}$ & $\begin{array}{c}\text { Área de } \\
\text { janela sala } \\
\left(\mathbf{m}^{2}\right)\end{array}$ & $\begin{array}{c}\begin{array}{c}\text { Área de } \\
\text { janela } \\
\text { cozinha } \\
\left(\mathrm{m}^{2}\right)\end{array}\end{array}$ & $\begin{array}{c}\text { Cor/ } \\
\text { refletância } \\
\text { parede A }\end{array}$ \\
\hline 1 & BASEB_NORTE & $0^{\circ} 90^{\circ} 180^{\circ} 270^{\circ}$ & 19.19 & 1.08 & 0.88 & Branco/ 0,9 \\
\hline 2 & JMAIORB_NORTE & $0^{\circ} 90^{\circ} 180^{\circ} 270^{\circ}$ & 19.19 & 1.5 & 0.92 & Branco/ 0,9 \\
\hline 3 & BASEC_NORTE & $0^{\circ} 90^{\circ} 180^{\circ} 270^{\circ}$ & 19.19 & 1.08 & 0.88 & Verde/ 0,76 \\
\hline 4 & JMAIORC_NORTE & $0^{\circ} 90^{\circ} 180^{\circ} 270^{\circ}$ & 19.19 & 1.5 & 0.92 & Verde/ 0,76 \\
\hline
\end{tabular}

Fonte: Autor (2013)

Foi necessário configurar dois planos de trabalho, um no ambiente sala e outro no ambiente cozinha, a fim de evitar que as simulações se estendessem desnecessariamente ao incluir o banheiro. Foi configurado um grid com aproximadamente $1 \mathrm{~m}^{2}$ de distância entre os pontos. Os quatro modelos construídos com as características descritas na tabela acima são apresentados a seguir (Figura 2).

Figura 2 - Os quatro modelos construídos no Troplux variando tamanho das aberturas (a e b) e cor de uma das paredes internas (c e d).

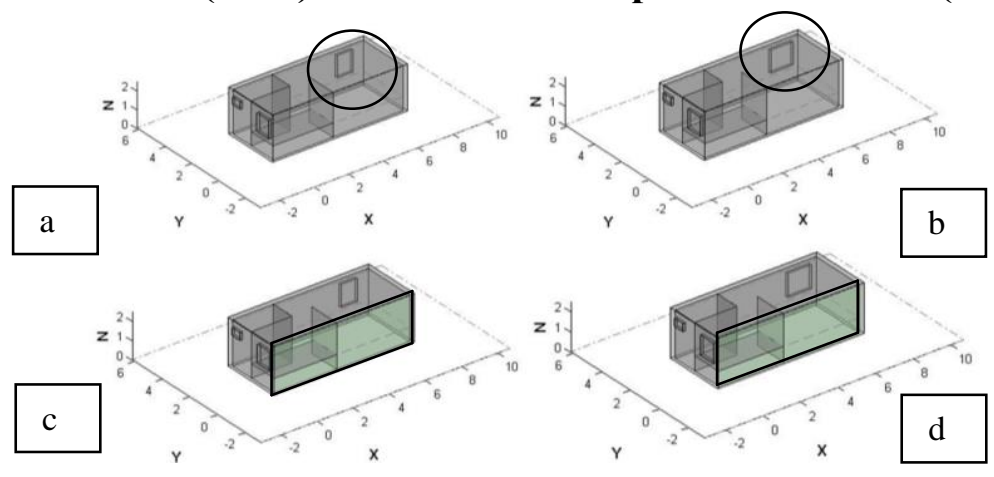

Fonte: Autor (2013) 
Os dados de entrada estão sintetizados no Quadro 2 e na Figura 3.

Quadro 2 - Dados de entrada inseridos no programa Troplux

\begin{tabular}{|c|c|}
\hline Latitude/Longitude & $\begin{array}{c}\text { Correspondentes à cidade de Maceió- } \\
\text { AL }\end{array}$ \\
\hline Período & Todos os dias do ano \\
\hline Horários & $7 \mathrm{~h}$ às $17 \mathrm{~h}$ (considerando hora solar) \\
\hline Refletância das superfícies internas & $\begin{array}{c}0,9, \text { exceto nos modelos } 3 \text { e } 4 \text { onde a } \\
\text { parede A tinha refletância de } 0,76 .\end{array}$ \\
\hline Iluminância difusa horizontal & $\begin{array}{c}\text { Illuminating Engineering Society of } \\
\text { North America (IESNA) }\end{array}$ \\
\hline Orientação & $0^{\circ}, 90^{\circ}, 180^{\circ}, 270^{\circ}$ \\
\hline Plano de trabalho & $\mathrm{a} 0.75 \mathrm{~m}$ do piso \\
\hline Margem de erro & $5 \%$ \\
\hline
\end{tabular}

Fonte: Autor (2013)

Figura 3 - Valores de Iluminância horizontal externa

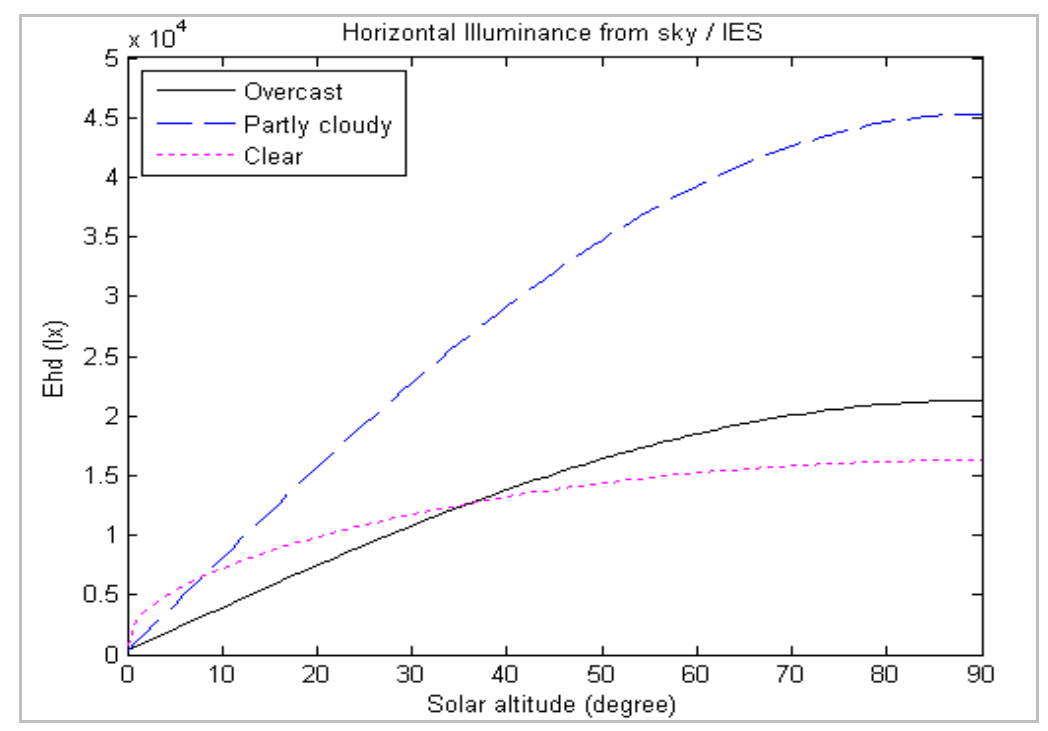

Fonte: Cabús (2010)

Para este trabalho foi analisada a iluminância média dos ambientes, a partir dos dados horários de iluminâncias, de todos dias do ano, das 7 às 17 horas, utilizando o céu dinâmico proposto pelo TropLux. Esta opção considera a variação real de tipos de céu padrão CIE, de hora em hora, baseada em uma distribuição estatística a partir dos dados meteorológicos de Maceió (CABÚS, 2012). Os padrões de céu escolhidos são os CIE 1 (encoberto), CIE 10 (parcialmente nublado) e CIE 14 (claro), considerados mais frequentes na cidade de Maceió, em estudo proposto por CABÚS (2002).

Os resultados obtidos nas simulações foram confrontados com os resultados da análise segundo o RTQ-R, a fim de verificar se as recomendações feitas pelo método prescritivo do Regulamento favorecem o desempenho da iluminação natural e consequentemente o conforto luminoso dos usuários no presente estudo. 


\section{RESULTADOS E DISCUSSÃO}

\subsection{Análise do pré-requisito e bonificação de iluminação natural segundo o RTQ- $\mathbf{R}$}

Para as análises do pré-requisito e bonificação propostos pelo RTQ-R, a sala e a cozinha foram consideradas como um ambiente único, seguindo a definição do Regulamento para ambiente. Foram calculadas, portanto, a área de piso e áreas efetivas para iluminação do ambiente. O Quadro 3 a seguir, mostra o cálculo do pré-requisito de iluminação natural, para as duas áreas de abertura para iluminação estudadas. A área de abertura efetiva para iluminação de $1,96 \mathrm{~m}^{2}$ corresponde à situação real dos edifícios do condomínio Mayra. A área de 2,42 $\mathrm{m}^{2}$ foi calculada em função do atendimento ao prérequisito.

\section{Quadro 3 - Verificação do pré-requisito de iluminação natural}

\begin{tabular}{|c|c|c|c|c|}
\hline $\begin{array}{c}\text { Ambiente de permanência } \\
\text { prolongada }\end{array}$ & Área de piso & $\begin{array}{l}\text { Área efetiva de } \\
\text { abertura para } \\
\text { iluminação }\left(\mathrm{m}^{2}\right)\end{array}$ & $\begin{array}{c}\text { Área } \\
\text { necessária } \\
(1 / 8 * A p)\end{array}$ & $\begin{array}{l}\text { Atende ao pré- } \\
\text { requisito } \\
\text { ILUMINAÇÃO? }\end{array}$ \\
\hline $\begin{array}{c}\text { Sala de estar/jantar }+ \\
\text { cozinha/serviço } \\
\text { (Modelo original) }\end{array}$ & 19,19 & 1,96 & 2,40 & NÃO \\
\hline $\begin{array}{l}\text { Sala de estar/jantar }+ \\
\text { cozinha/serviço } \\
\text { (Modelo modificado) }\end{array}$ & 19,19 & 2,42 & 2,40 & SIM \\
\hline
\end{tabular}

Fonte: Autor (2013)

Verificou-se ainda que o ambiente estudado atende às exigências de profundidade e refletância do teto superior a $60,00 \%$, considerando que a cor do teto é branca, com refletância de aproximadamente $90,00 \%$.

Segundo os cálculos, a profundidade do ambiente deve ser inferior ou igual a 5,04 m para atender à exigência. De acordo com o RTQ-R, quando há mais de uma abertura, considera-se o menor valor de distância entre a abertura e a parede oposta. Nesse caso, a profundidade é de 3,00 m (Quadro 4).

Quadro 4 - Verificação da bonificação de iluminação natural

\begin{tabular}{|c|c|c|c|c|c|}
\hline \multicolumn{4}{|c|}{ Profundidade (P $\leq \mathbf{2 , 4}$. ha $)$} & Refletância do teto acima de 60\% \\
\hline Ambiente & P & ha & $\mathbf{2 , 4 . ~ h a ~}$ & Atende? & Atende? \\
\hline $\begin{array}{c}\text { Sala de estar/ jantar } \\
\text { e cozinha/ serviço }\end{array}$ & 3,00 & 2,10 & 5,04 & SIM & SIM \\
\hline
\end{tabular}

Fonte: Autor (2013)

\subsection{Análises paramétricas por meio de simulação computacional no software TropLux}

Sobre o aumento das aberturas, os Gráficos 2 e 3 mostram as iluminâncias na Sala para o modelo 001: janelas reais do edifício e para o modelo 002: janelas aumentadas para atender o pré-requisito do RTQ-R, de acordo com as variações na orientação dos modelos. Conforme esperado, houve um aumento das iluminâncias no ambiente. Nota- 
se que a iluminância média cresce $42,40 \%$. A máxima cresce $38,40 \%$ enquanto a mínima absoluta cresce $34,00 \%$.

\section{Gráficos 2 e 3 Valores de iluminância média, mínima e máxima na Sala para os modelos 1 (original) e 2 (modificada), em quatro orientações distintas}

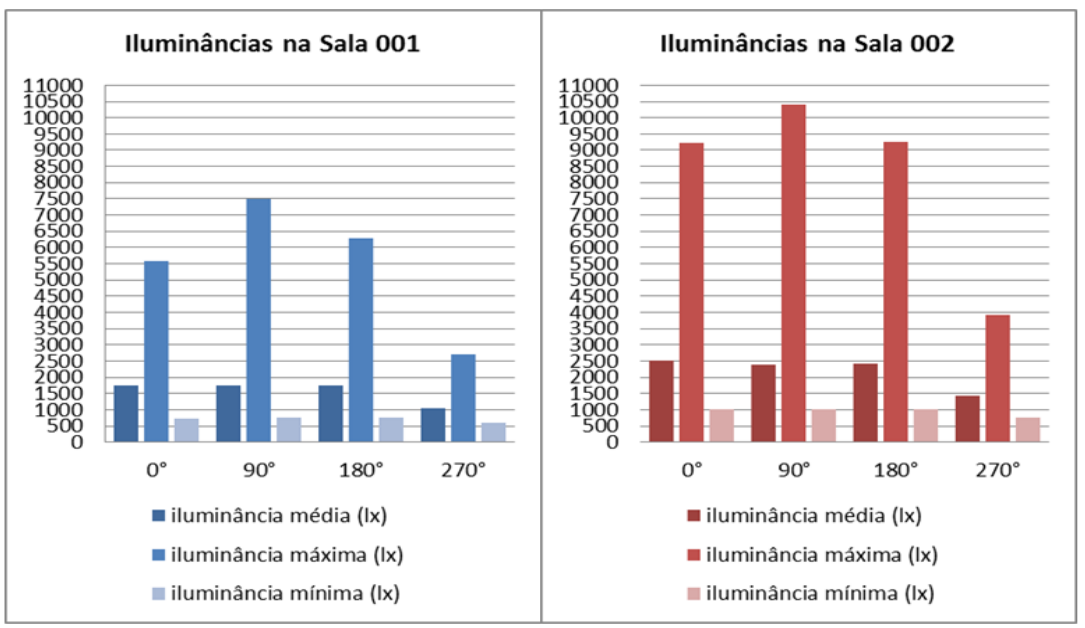

Fonte: Autor (2013)

Os Gráficos 4 e 5 mostram as iluminâncias na Cozinha para os modelos 1 e 2. Da mesma forma que na Sala, houve um aumento das iluminâncias no ambiente, porém menos significativo. A iluminância média máxima cresce 7,50\%. A máxima absoluta cresce $3,70 \%$ enquanto a mínima absoluta cresce $9,40 \%$.

Verificou-se que a variação nos valores de iluminância foi maior na sala do que na cozinha, pelo fato de que a abertura da sala foi aumentada em $28,00 \%$, enquanto que a abertura da cozinha em $4,34 \%$, devido ao espaço disponível em planta para a ampliação das janelas, de maneira que a soma das áreas de iluminação natural atendessem ao prérequisito do RTQ-R para iluminação natural. Além disto, observa-se nos gráficos 2 e 4 que apesar de não atender ao pré-requisto de área de abertura mínima para iluminação natural segundo o RTQ-R, os ambientes apresentam iluminâncias adequadas ao uso.

\section{Gráficos 4 e 5 Valores de iluminância média, mínima e máxima na Cozinha para os modelos 1 (original) e 2(modificada), em quatro orientações distintas}

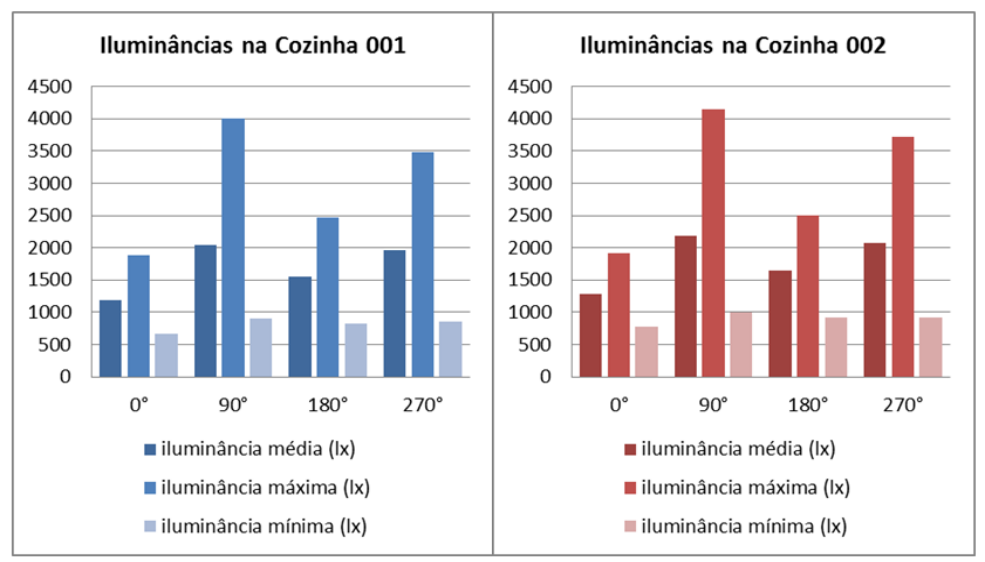

Fonte: Autor (2013) 
Os Gráficos 6, 7, 8 e 9 a seguir, mostram os resultados obtidos para os percentuais de horas no ano em que é registrada cada faixa de iluminância correspondente ao regime UDI adotado (insuficiente, suficiente, desejável e excessiva), sob condições de céu dinâmico, somando-se as quatros orientações simuladas.

\section{Gráficos 6, 7, 8 e 9 Valores de iluminância por intervalos nas Salas 001 (original) e 002 (modificada), e Cozinhas 001 (original) e 002 (modificada), para quatro orientações distintas.}

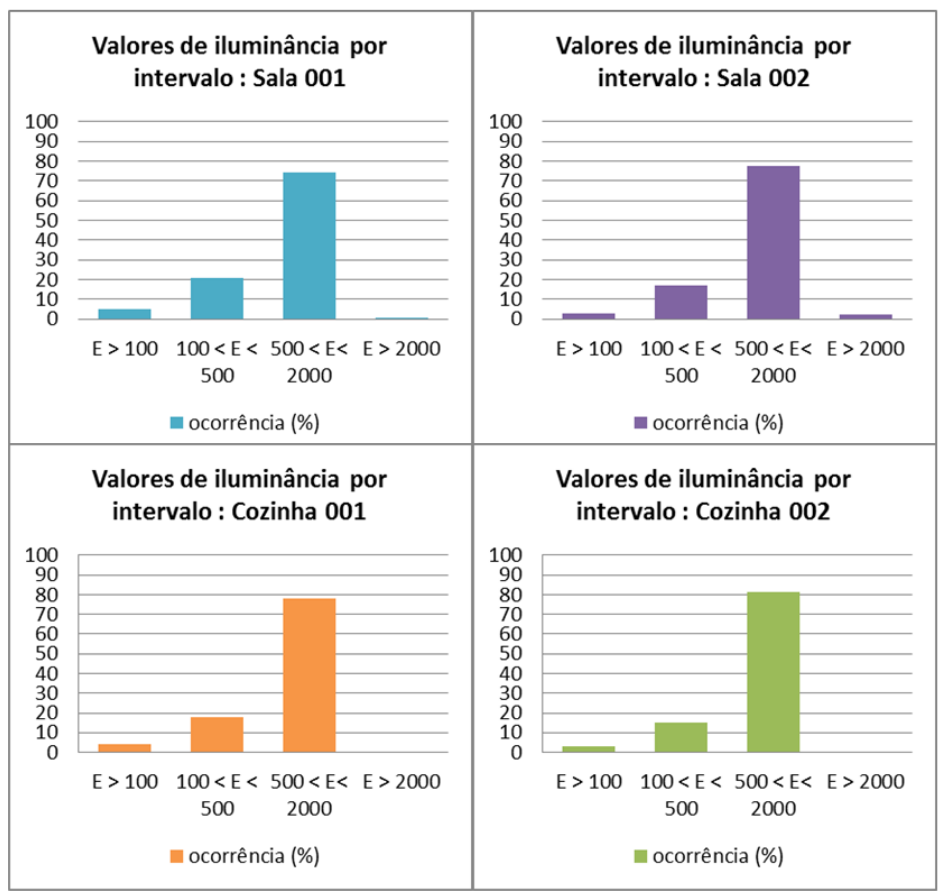

Fonte: Autor (2013)

A sala 001 refere-se ao modelo com área e janelas originais. A sala 002 refere-se ao modelo com janelas aumentadas para atender o pré-requisito de iluminação natural do RTQ-R.

Observa-se que os índices de iluminância desejável, entre 500 e 2000 lx, ocorreram com $74,34 \%$ de frequência em todas as orientações avaliadas no modelo com as janelas reais do edifício em estudo. No modelo com a área efetiva de iluminação aumentada, ocorreu aumento da ocorrência dos valores de iluminância nesta mesma faixa $(77,76 \%)$.

Na cozinha houve aumento da ocorrência de iluminâncias acima de 1001x em 24,40\%, aumento das iluminâncias entre 100 e 500 lx de 18,00\% e diminuição das iluminâncias acima entre 500 e 2000 lx de 4,00\%. Não houve ocorrência de iluminâncias acima de 2000 lx. Na sala, houve aumento da ocorrência de iluminâncias acima de 1001x em 64,20\%, aumento das iluminâncias entre 100 e 500 1x de 21,60\% e diminuição das iluminâncias acima entre 500 e 2000 lx de 4,60\%.

Na cozinha os valores de iluminância se mantiveram na mesma faixa, entre 500 e 2000 $1 \mathrm{x}$, tanto no modelo com área igual a das janelas reais, quanto no modelo com área aumentada. Houve apenas um aumento da frequência de iluminâncias nessa faixa passando de $77,96 \%$ para $81,49 \%$.

As simulações com diferentes orientações não apresentaram variações significativas entre os modelos. 
Quanto à mudança de cor na parede, os Gráficos 10,11, 12 e 13 mostram os resultados comparativos entre o modelo com aberturas redimensionadas segundo o RTQ-R, de paredes brancas e o mesmo modelo com uma das paredes coloridas com refletância de 0,76 .

Tanto na sala quanto na cozinha, houve um aumento nos índices de iluminância. Na sala a iluminância média máxima cresceu $29,50 \%$ e na cozinha a iluminância média máxima cresceu $7,40 \%$ conforme os gráficos a seguir.

\section{Gráficos 10 e 11 Valores de iluminância média, mínima e máxima na Sala, para os modelos 2 e 4, em quatro orientações distintas}

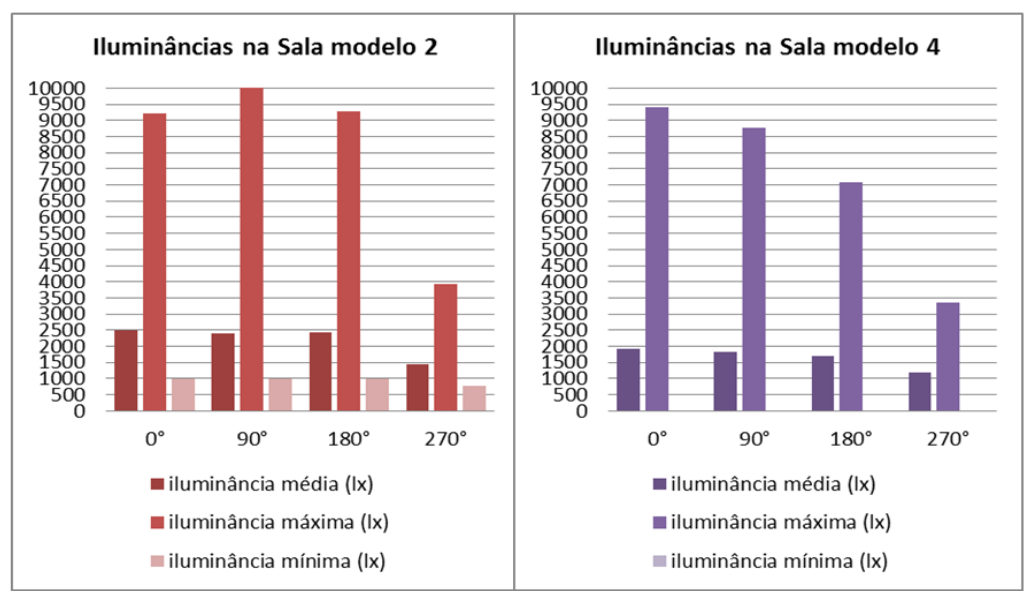

Fonte: Autor (2013)

\section{Gráficos 12 e 13 Valores de iluminância média, mínima e máxima na Cozinha,} para os modelos 2 e 4, em quatro orientações distintas

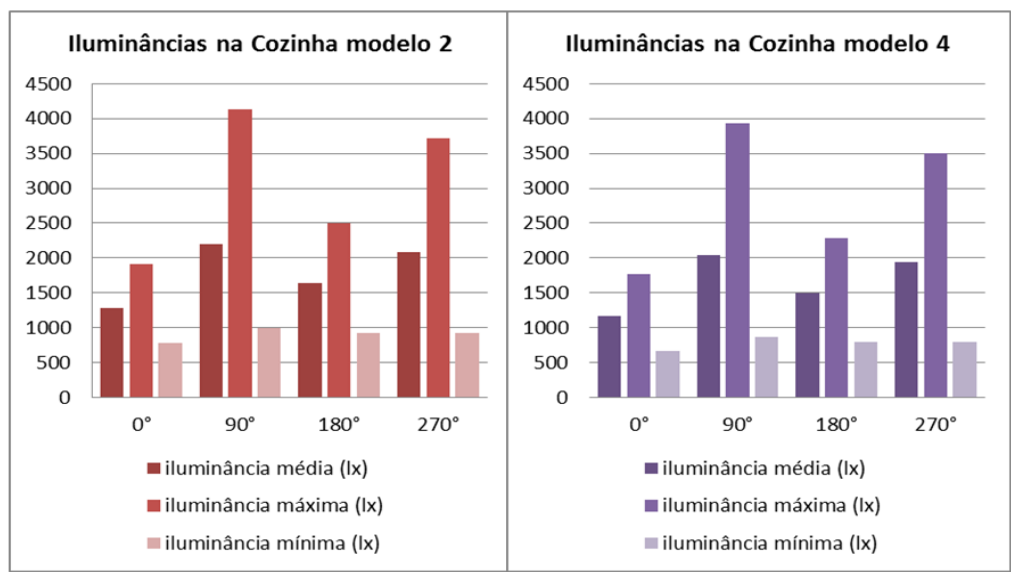

Fonte: Autor (2013)

Foi verificado que a mudança na cor de uma das paredes internas não trouxe prejuízo para a distribuição da iluminação natural, pois as iluminâncias se mantiveram na mesma faixa.

Por meio dos resultados obtidos, observa-se que os valores de iluminância por intervalo são em maior parte considerados desejáveis, com ocorrências entre 70,00\% e 80,00\%, independente de os ambientes atenderem ou não ao pré-requisito de iluminação natural. $\mathrm{Na}$ avaliação da configuração real das janelas, os ambientes não atendem ao pré- 
requisito de iluminação natural do RTQ-R, mas apresentam iluminâncias adequadas ao uso.As mudanças das áreas de abertura para iluminação natural, da cor da parede e da orientação solar, não causaram prejuízo no desempenho da iluminação natural nos ambientes analisados.

\section{CONCLUSÕES}

O presente trabalho traz um estudo em ambientes de permanência prolongada de edifícios habitacionais populares na cidade de Maceió-AL. Após simulações com o software TropLux 6.0, foram analisados os valores de iluminância interna em conjunto com a verificação de pré-requisito e bonificação propostos pelo RTQ-R para iluminação natural em edificações residenciais. Foram analisados os aspectos: aumento da área das aberturas e mudança de refletância de uma das paredes internas ao modelo de branco para verde, além de diferentes orientações.

As simulações mostraram que os valores de iluminância, apesar de ligeiramente maiores com o aumento das aberturas, permaneceram na mesma faixa de ocorrência entre $100 \mathrm{e}$ 2000 lx. As mudanças na orientação não representaram diferenças significativas nos valores de iluminância. A mudança do branco com refletância 0,9 para o verde com refletância 0,76 diminuiu as iluminâncias do ambiente em até 29,50\%, mas os valores continuaram dentro dos limites desejáveis.

O programa computacional utilizado se mostrou eficiente na análise paramétrica dos aspectos estudados. As diversas formas de análise dos dados de saída oferecidos pelo programa facilitaram a investigação.

Segundo o RTQ-R, o único critério não obedecido foi o da área das aberturas e foi este o principal critério escolhido para a simulação neste trabalho. Entretanto, sugere-se para trabalhos futuros, a simulação de ambientes com diferentes profundidades e refletâncias do teto abaixo de $60,00 \%$, o que ocasionaria a perda de pontos de bonificação segundo o Regulamento.

\section{REFERÊNCIAS}

ASSOCIAÇÃO BRASILEIRA DE NORMAS TÉCNICAS. ABNT. NBR 5413: Iluminância de Interiores. Rio de Janeiro, Brasil, 1992.

BRASIL. Ministério do Desenvolvimento, Indústria e Comércio Exterior. Instituto Nacional De Metrologia, Normalização e Qualidade Industrial - INMETRO. Portaria n. ${ }^{\circ}$ 18, de 16 de janeiro de 2012. Rio de janeiro: [S.ed], 2012.

CABÚS, R. C. Tropical Daylighting: predicting sky types and interior illuminance in north-east Brazil. (PhD).Architecture University of Sheffield, Sheffield, 2002.288p.

CABÚS, R. C. TropLux: um sotaque tropical na simulação da luz natural em edificações. In: IV Encontro Latino-Americano e VIII Encontro Nacional Sobre Conforto no Ambiente Construído, Maceió, 2005, Anais...Maceió, ENCAC-ELAC 2005-a.CD-ROM.

Validação do Programa Troplux. In: IV Encontro Latino-Americano e VIII Encontro Nacional Sobre Conforto no Ambiente Construído, Maceió, 2005, Anais...Maceió, ENCAC-ELAC 2005-b.CD-ROM.

TropLux, versão 6: Guia do Usuário, Maceió: Grilu, 2012.

GHISI, E. TINKER, J. A. An Ideal Window Area concept for energy effcient integration of daylight and artificial light in buildings. Energy and Buildings, v. 40. 2005. P. 51-p. 61. 